Ann. Biol. anim. Bioch. Biophys., I968, 8 (3), 407-4I7.

\title{
ORIGINE DES ANTICORPS DU LAIT
}

\author{
M. PLOMMET \\ avec la collaboration technique de Anne-Marie Plommet \\ Station de Pathologie de la Reproduction, \\ Centre de Recherches vétérinaires et zootechniques de Tours-l'Orfrasière, 37 - Nouzilly \\ Institut national de la Recherche agronomique
}

\section{SOMMAIRE}

Des brebis ont été vaccinées par injection d'antigènes dans la mamelle (vaccination locale) ou par voie sous-cutanée (vaccination générale); les anticorps correspondants ont été titrés dans le sérum et le lactosérum.

Après vaccination générale à l'aide des antigènes cellulaires de Salmonella et de Brucella, il y a une régression des titres des anticorps du lactosérum sur les titres du sérum, telle que les premiers sont environ 25 fois plus petits que les derniers. Cette relation n'est pas affectée par l'injection dans la mamelle d'antigènes différents.

Après vaccination locale à l'aide de l'antigène de Brucella, les titres des agglutinines dans le lait montent jusqu'à atteindre en moyenne la moitié des titres du sérum. La vaccination locale à l'aide des antigènes staphylococciques, anatoxines et corps microbiens, ne modifie pas la relation des titres correspondants du sérum et du lactosérum. Ainsi, les anticorps du lait peuvent venir du sérum par passage à travers la mamelle, ou après injection de certains antigènes dans la mamelle, venir d'un processus de synthèse locale.

\section{INTRODUC'TION}

L'origine des anticorps du lait est une question controversée (LASCELLES, I963; Campbeli, et Petersen, ig63).

Pour les uns, les anticorps présents dans le colostrum et dans le lait ont une origine sérique. Les anticorps passent ou " filtrent" du sérum dans la mamelle, subissant parfois au passage une modification de structure (DIXON, WEIGLE et VASquez, I96I ; Pierce et Feinstein, I965; Asofsky et Smali, I967). Le taux de passage varie selon l'état physiologique et éventuellement pathologique de la mamelle; pendant la période colostrale, il y a concentration des anticorps dans la mamelle, puis passage à taux faible pendant la lactation ; l'inflammation de la mamelle augmente considérablement le passage des anticorps, et d'une manière plus générale, des $\gamma$-globulines et albumines sériques.

Pour les autres, les anticorps du lait sont formés localement, dans le système lymphatique mammaire, quand la stimulation antigénique a lieu dans la mamelle (Thomas et Leclerc, I96I ; Sarwar, Campbel , et Petersen, I964; Mitcheli, 
I965). Pendant longtemps cette hypothèse a été soutenue par l'équipe de CAMPBELL et Peterens (I963) en se basant sur le fait, discutable, de l'apparition d'anticorps spécifiques dans le lait immédiatement après l'injection d'un antigène dans la mamelle. Pour les tenants de la première hypothèse, ce fait doit être expliqué par l'augmentation de passage due à l'inflammation, résultant elle-même de l'injection d'antigène. C'est, en effet, au refus de considérer le tôle de l'inflammation dans ce phénomène, ou au moins à l'absence d'un moyen de mesure de son rôle, que l'on doit le discrédit dans lequel l'hypothèse de la synthèse d'anticorps dans la mamelle est tenue.

$\mathrm{Si}$ les anticorps du lait viennent du sérum sanguin, par passage à travers le tissu mammaire, il doit exister un rapport constant entre le titre d'un anticorps donné dans le sang et son titre dans le lait, en dehors de la période colostrale et en l'absence d'inflammation. Si ce rapport est effectivement constant, on dispose alors d'un moyen de mesurer le passage des anticorps, et par conséquent d'en estimer les modifications telles que celles dues à l'inflammation résultant de l'injection intramammaire d'un antigène. En utilisant deux systèmes antigènes-anticorps différents, l'un obtenu par vaccination par voie générale et servant à la mesure du passage et l'autre obtenu par injection intramammaire d'antigène, il devient possible d'établir si les anticorps du lait de ce deuxième système résultent ou non, d'une modification non spécifique du passage et de vérifier, par conséquent, si 1'hypothèse de la synthèse locale doit être retenue ou pas.

\section{MATÉRIEL, E'T MÉTHODES}

\section{Schéma des expériences (tabl. I)}

Dans une première expérience, on a comparé les rapports des titres de plusieurs anticorps spécifiques dans le sérum au titre des mêmes anticorps dans le lactosérum. L'expérience a porté sur

\section{TABLEAU I}

Schéma des expériences

Antigènes et anticorps S. Salmonella, agglutinines $\mathrm{O}$ et $\mathrm{H}$.

B. Brucella, agglutinines.

A. Anatoxines $\alpha$ et $\beta$ staphylococciques et antitoxines correspondantes.

C. Staphylocoque, corps microbiens et agglutinines.

\begin{tabular}{|c|c|c|c|c|c|}
\hline Expériences & \multicolumn{2}{|c|}{1} & \multicolumn{3}{|c|}{2} \\
\hline Lots & $\begin{array}{c}1 \\
\text { témoin }\end{array}$ & 2 & 3 & 4 & $\stackrel{5}{\text { témoin }}$ \\
\hline Antigène marqueur ..... & $S$ et $B$ & $\mathrm{~S}$ et $\mathrm{B}$ & $S$ & $\mathrm{~S}$ & $\mathrm{~S}$ \\
\hline $\begin{array}{l}\text { Antigène testé } \ldots \ldots \ldots \ldots \\
\text { Lieu injection } \ldots \ldots \ldots \\
\text { Période de lactation } \ldots\end{array}$ & - & $\begin{array}{l}\text { A. C. } \\
\text { mamelle } \\
\text { lactation }\end{array}$ & $\begin{array}{c}\text { A. B. } \\
\text { mamelle } \\
\text { avant lactation }\end{array}$ & $\begin{array}{l}\text { A. B. } \\
\text { mamelle } \\
\text { lactation }\end{array}$ & $\begin{array}{l}\text { A. B. } \\
\text { sous-cutanée } \\
\text { avant lactation }\end{array}$ \\
\hline Données enregistrées & \multicolumn{2}{|c|}{$\begin{array}{l}\text { Passage Ac marqués } \mathrm{S}(\mathrm{O} \text { et } \mathrm{H}) \\
\text { et } \mathrm{B} \text { avec ou sans vacc. local. } \\
\text { Rapport des titres sérum/lac- } \\
\text { tosérum. }\end{array}$} & \multicolumn{3}{|c|}{$\begin{array}{l}\text { Rapport des titres sérum-lactosérum des anti- } \\
\text { corps A.B. Le passage de } \mathrm{S}(\mathrm{O} \text { et } \mathrm{H}) \text { n'étant } \\
\text { pas modifié par la vaccination avec } \mathrm{A} \text {. B. }\end{array}$} \\
\hline
\end{tabular}


27 brebis, le $5^{8^{\mathrm{e}}}$ jour de la lactation. Ces brebis, réparties en un lot témoin (lot $\mathrm{I}, \mathrm{I}_{5}$ brebis) et un lot expérimental (lot 2, 12 brebis), avaient reçu au préalable des injections par voie générale de deux vaccins marqueurs (vaccin Salmonella $\mathrm{S}$, et vaccin Brucella B). Les brebis du lot 2 avaient reçu en outre par voie intramammaire, pendant la lactation, des injections d'un vaccin staphylococcique (Vaccin A. C. : anatoxines, A et corps microbiens, C).

Dans une deuxième expérience, on a comparé de la même manière les titres des anticorps du sérum et du lactosérum sur $2 \mathrm{I}$ brebis, à 7 reprises, au cours des $\mathrm{I} 2$ premières semaines de la lactation. Ces brebis, réparties en 3 lots, avaient toutes reçu des injections par voie générale du vaccin marqueur S. Elles avaient reçu, en outre, des injections de mêmes doses d'un vaccin anatoxines staphylococciques - Brucella (vaccin A. B.) - soit :

I. par voie sous-cutanée, avant le début de la lactation (lot 5, 9 brebis) ;

2. dans la mamelle, pendant la période sèche (lot 3,6 brebis);

3. dans la mamelle, pendant la lactation (lot 4,6 brebis).

Toutes les brebis en expérience étaient exemptes d'infection et d'inflammation mammaire, ce qui a été établi par les méthodes bactériologiques et cytologiques décrites précédemment (PLOMmET, LE GALL, I963 a).

\section{Vaccins et vaccinations}

\section{a) Vaccin $S$}

$2 \cdot 10^{8}$ cellules/ml Salmonella abortus ovis, récolté sur Tryptose blood agar base Difco, lavé, filtré, formolé à $0,5 \mathrm{p}$. 100 pendant 24 heures, puis suspendu en solution saline formolée à $0,05 \mathrm{p}$. I00.

- Vaccination : 3 injections sous-cutanées de 0,52 et $5 \mathrm{ml}$ à 8 jours d'intervalle avant l'agnelage, suivies d'une injection de rappel de $5 \mathrm{ml}$ le $44 \pm 4^{\mathrm{e}}$ jour de la lactation.

\section{b) Vaccin $B$}

5. $\mathrm{I}^{9}$ cellules/ml Brucella abortus B. I 9 cultivé sur Brucella agar Albimi, préparé commeci-dessus, avec séjour de 48 heures en solution formolée à $0,5 \mathrm{p}$. 100. Vaccination par voie sous-cutanée, aux mêmes doses que ci-dessus.

\section{c) $\operatorname{Vaccin} A$}

Vaccin commercial constitué par un mélange d'anatoxines staphylococciques $\alpha$ et $\beta$, titrant respectivement Io et 5 unités (Institut Pasteur).

A ce vaccin on a ajouté des cellules bactériennes, soit du vaccin B pour obtenir $5.10^{8}$ cellules $/ \mathrm{m} 1$ (vaccin A. B.), soit du Staphylococcus aureus, souche 81.26, récolté sur Tryptose blood Agar base Difco, chauffé à $100^{\circ}$ pendant 5 minutes, lavé et remis en suspension en solution formolée, à 0,05 p. I00, pour obtenir $2.10^{\circ}$ cellules/ml (vaccin A. C.).

- Vaccination : 4 injections de $2 \mathrm{ml} \mathrm{de} \mathrm{A.} \mathrm{B.} \mathrm{ou} \mathrm{A.} \mathrm{C.} \mathrm{à} 5$ jours d'intervalle sous-cutanées, soit intramammaires ( $1 \mathrm{ml}$ dans chaque quartier) avant ou au début de la lactation, selon le lot, puis dans tous les lots une injection sous-cutanée de rappel le $44 \pm 4^{\mathbf{e}}$ jour de la lactation.

\section{Titrage des anticorps}

Titrage des anticorps du sérum et du lactosérum (ce dernier obtenu par coagulation par la présure) :

a) par agglutination :

- antigènes $\mathrm{O}$ et $\mathrm{H}$ de $S$. abortus ovis (méthode de Félix);

- antigène standard de B. aborius (C. R. F. O. Montpellier);

- antigène staphylococcique selon PILLET, ORTA et FouCAUd (rg6o).

b) par inhibition de l'hémolyse, avec les toxines staphylococciques $\alpha$ et $\beta$, selon la technique décrite précédemment (Plommet et Le GaLL, $1963 b$ ).

Ces anticorps agglutinants ou neutralisants sont désignés par les mêmes abréviations que les antigènes correspondants.

Les titres sont exprimés par le $\log _{2}+$ I de la réciproque de la dilution donnant $5^{\circ} \mathrm{p}$. Ioo d'agglutination ou d'hémolyse. Cette notation correspond, dans un système de dilution de $1 / 2$ en $1 / 2$, au numéro d'ordre du tube. Le tube I est le témoin sérum, et le titre I correspondant signifie "plus petit que $r / 2 \%$. Le titre 2 équivaut ainsi à $\mathrm{I} / 2,3$ à $r / 4$, etc. Tous les titrages ont été faits en double. 


\section{RÉSULTATS}

I. Relations entre les titres anticorps du sérum et du lactoserum après vaccination par voie générale

a) Cas général.

La relation entre les titres des agglutinines salmonelliques $\mathrm{O}$ et $\mathrm{H}$ et brucelliques du sérum et du lactosérum des brebis de l'expérience I est représentée sur la figure $I$. Ces valeurs, obtenues le $5^{8} \pm \mathbf{I}^{\mathbf{e}}$ jour de la lactation comprennent les brebis des lots I et 2 . En effet, bien que les brebis du lot 2 aient reçu dans la mamelle le

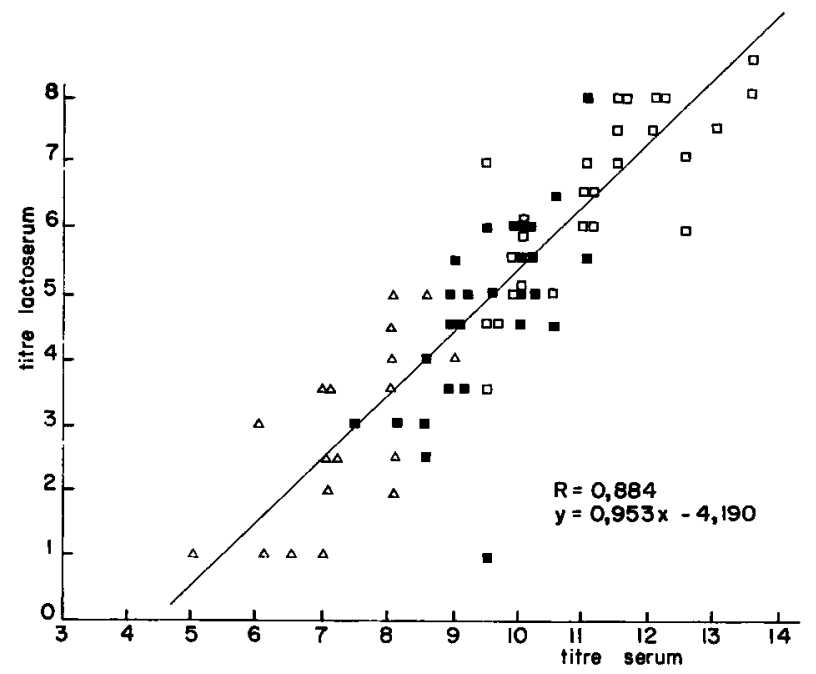

FIG. I. - Régression des tilres des agglulinines brucelliques et salmonelliques $O$ et $H$ du lactosérum sur les titres du sérum

Titres exprimés en $\log _{2}+$ I des dilutions donnant 50 p. 100 d'agglutination ○ Salmonella $\mathbf{H}$, Salmonella $0, \Delta$ Brucella

vaccin staphylococcique A. C., cette vaccination n'a pas modifié sensiblement les rapports des titres sérum sur lactosérum des anticorps salmonelliques et brucelliques. Le coefficient de corrélation global a pour valeur $R=0,884$, et les coefficients par lots $R_{1}=0,904$ et $R_{2}=0,853$.

La régression des titres du lactosérum $(y)$ sur ceux du sérum $(x)$ a pour équation :

$$
y=0,953 x-4,19 \text {. }
$$

En admettant en première approximation que le coefficient « $a$ » soit égal à $I$, la différence $x-y$ est constante, soit une différence de titre entre sérum et lactosérum constante, égale à 4,2 dilutions. En réalité $a=0,953$, ce qui dans les limites de l'expérience donne une différence de titre variant de 4,44 pour $y=\mathrm{I}$ à 4,79 pour $y=8$, avec une moyenne de 4,63 pour $y=4,5$.

En exprimant cette différence des valeurs logarithmiques par le rapport des 
valeurs arithmétiques, on a un rapport variant de 21,7 à 27,7 avec une valeur moyenne de 24,8 . En d'autres termes, les titres du lactosérum sont en moyenne 25 fois plus petits que ceux du sérum.

b) Influence du stade de lactation.

Les différentes valeurs du rapport (exprimé par la différence des titres en logarithmes) des titres sérum sur lactosérum des agglutinines salmonelliques $O$ et $H$, au cours des I2 premières semaines de la lactation des brebis de l'expérience 2 (lots 3 , 4 et 5 ) sont indiquées sur les figures 2 et 3 . On voit que pendant cette période, il n'y a pas de variations notables et systématiques de ce rapport, qui reste autour des valeurs 4 et 5 (soit Iú et 32 en valeur arithmétique).

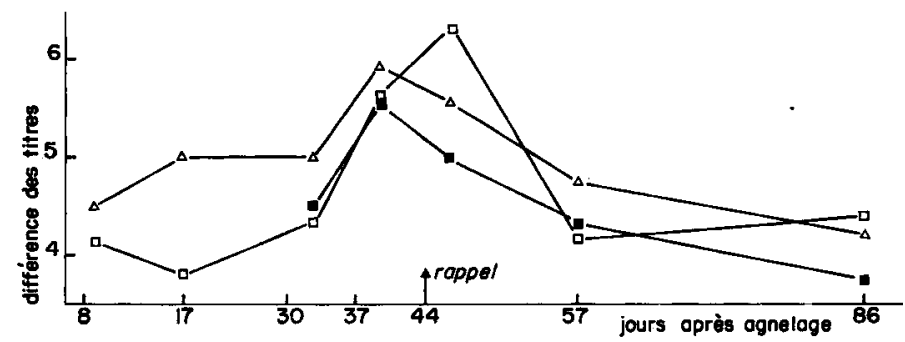

Fig. 2. - Evolution du rapport des titres des agglutinines salmonelliques $O$ du sérum aux titres du lactosérum, au cours de la lactation, sur des brebis ayant reçu l'antigène par voie générale Rapport représenté par la différence des titres sérum moins lactosérum exprimée en $\log _{2}$ de la dilution $\square \operatorname{lot} 3, \square \operatorname{lot} 4, \Delta \operatorname{lot} 5$ (témoin)

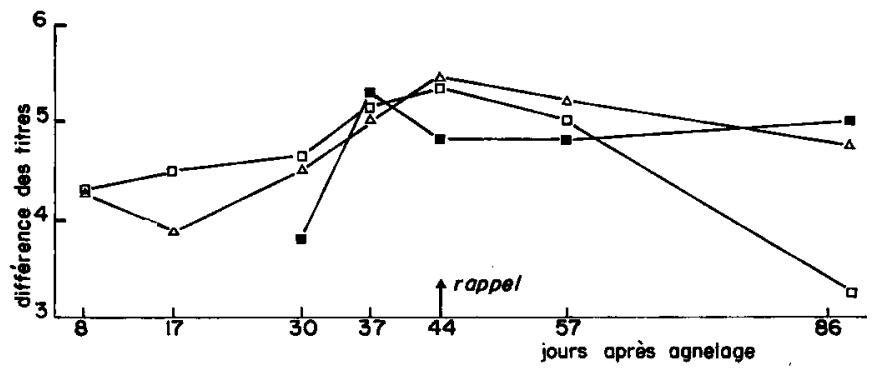

Fig. 3. - Evolution du rapport des titres des agglutinines salmonelliques $H$ (cf. fig. 2) $\square$ lot $3,-\operatorname{lot} 4, \Delta$ lot 5 (témoin)

c) Influence de la vaccination intramammaire avec antigènes différents de ceux utilisés pour le marquage des anticorps.

Nous avons noté ci-dessus que la corrélation entre les titres sérum sur lactosérum des brebis du lot 2 , étaient légèrement moins bonne que celle des brebis du lot $\mathrm{I}$, sans que la différence soit significative. Ceci peut être attribué à l'inflammation due à la vaccination intramammaire, faite avec le vaccin $A$. C. sur les brebis du lot 2. Cette influence - si elle existe - est en réalité très faible à ce stade de la lactation, c'est-à-dire 37 jours après la dernière injection locale de vaccin, puisqu'elle ne modifie pratiquement pas le rapport des titres, mais seulement la dispersion des résultats. 
De la même manière, les rapports des titres des agglutinines marquées (salmonelliques $\mathrm{O}$ et $\mathrm{H}$ ), de la $2^{\mathrm{e}}$ expérience (fig. 2 et 3 ) ne sont pas sensiblement différents dans les lots 3, 4 et 5, ayant reçu ou non le vaccin A. B. dans la mamelle. Dans cette expérience, il s'est écoulé seulement 7 jours entre la vaccination intramammaire du lot 4 et le prélèvement $n^{0} 3$ des figures.

Ces résultats montrent que si les vaccins utilisés par voie locale provoquent une certaine irritation, celle-ci n'a qu'une influence temporaire, non décelable après un certain temps, sur le passage des anticorps du sérum dans le lactosérum.

\section{Relation entre les titres anticorps du sérum et du lactosérum après vaccination intramammaire}

a) Antigènes staphylococciques, anatoxines et corps microbiens.

Les titres des antitoxines $\alpha$ et $\beta$ et des agglutinines staphylococciques du sérum et du lactosérum de la première expérience ne s'écartaient pas, en première approximation, de la régression de la figure I. Les titres dans le lactosérum étaient le plus souvent trop bas pour être mesurés avec précision.

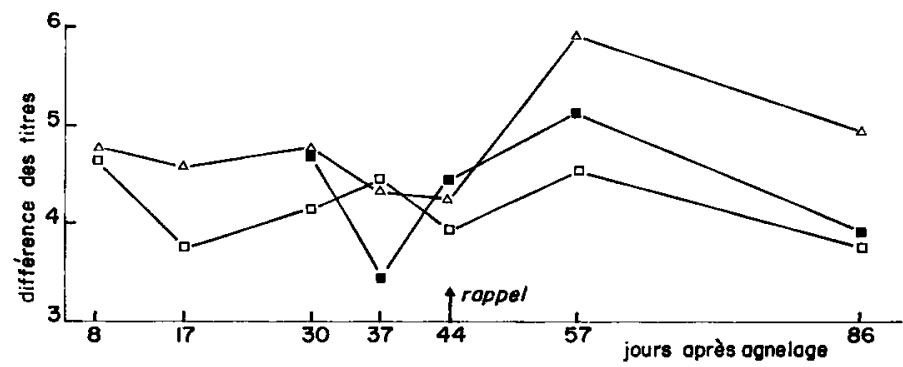

Fig. 4. - Évolution du rapport des titres des antitoxines staphvlococciques $\alpha$ du sérum aux titres du lactosérum, au cours de la lactation, sur des brebis ayant rȩ́u l'antigène par voie générale (lot 5), ou dans la mamelle (lots 3 et 4 )

$\square$ lot $3, \square \operatorname{lot} 4 . \Delta$ lot 5, (témoin)

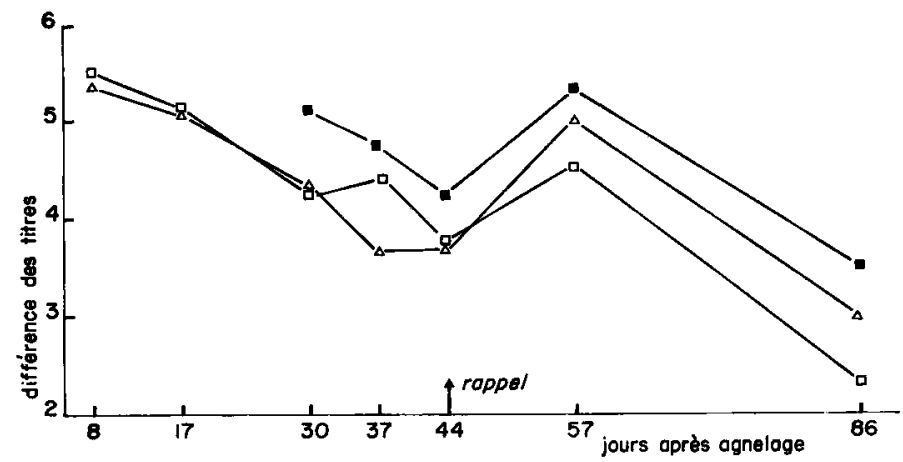

FiG. 5. - Evolution du rapport des tilres des antitoxines staphylococciques $\beta$ (cf. fig. 4) $\square$ lot 3 , . lot $4, \Delta$ lot 5 (témoin)

Les résultats de la $2^{\text {e }}$ expérience (fig. 4 et 5 ) montrent que les rapports des titres sérum sur lactosérum restent voisins des valeurs $4-5$, que le vaccin $A$. B. ait été injecté par voie générale (lot 5) ou dans la mamelle (lots 3 et 4). 
On constate cependant une élévation nette du rapport (jour 57) après l'injection générale de rappel faite le $44^{\mathrm{e}}$ jour, élévation qui résulte d'une remontée temporaire des titres du sérum sans répercussion notable sur les titres du lactosérum, et ceci que la stimulation primaire ait eu lieu dans la mamelle ou par voie générale.

Ces faits montrent qu'avec ce type d'antigène, il n'y a pas lieu d'envisager l'hypothèse d'une synthèse locale ; toutefois, l'influence de l'injection de rappel suggère que le passage du sérum vers le lactosérum ne suit pas une loi simple à taux constant, tel que cela pourrait avoir lieu s'il s'agissait d'une simple filtration.

Il faut ajouter à ces faits que le titre des antitoxines sériques est en moyenne plus élevé dans les lots vaccinés dans la mamelle que dans les lots vaccinés par voie sous-cutanée pour une même dose d'antigène. Par exemple, au prélèvement $n^{0} 4$, les titres anti- $\alpha$ ont pour moyenne, dans les lots 3 et $4: 12,83$ et I4,66 contre II,I dans le lot 5 . La comparaison $3+4$ versus 5 est significative $(F=6,52$ avec $F$ $0,05=4,38$ ).

b) Antigène brucellique.

Le rapport des titres des agglutinines du sérum sur lactosérum obtenus dans la $2^{\mathbf{e}}$ expérience sont indiqués figure 6 .

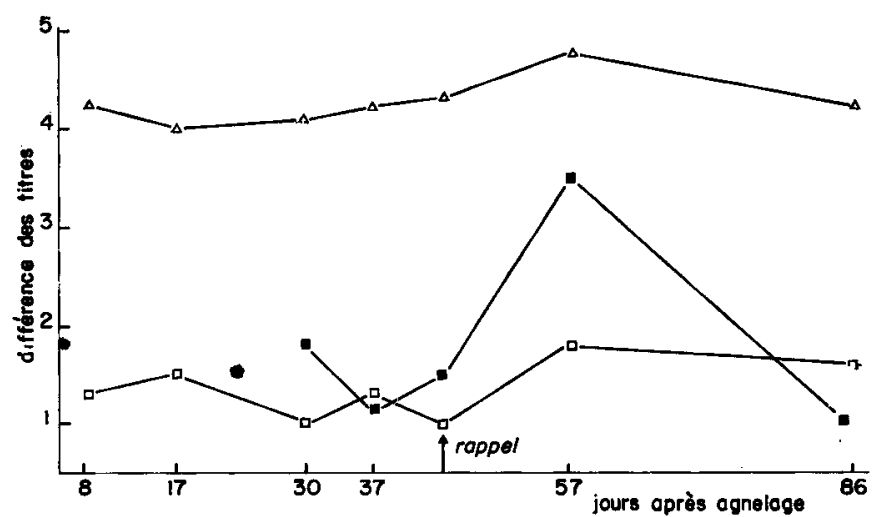

Fig. 6. - Evolution du rapport des titres des agglutinines brucelliques du sérum aux litres du laclosérum, au cours de la lactation, sur des brebis ayant reçu l'antigène par voie générale (lot 5) ou dans la mamelle (lots 3 et 4)

$\square \operatorname{lot} 3, \square \operatorname{lot} 4, \Delta \operatorname{lot} 5$ (témoin)

Dans le cas des brebis vaccinées par voie générale (lot 5), le rapport a une valeur voisine de 4,2 , constante au cours de la lactation, valeur identique à celle obtenue dans la première expérience.

Par contre, dans le cas des brebis vaccinées dans la mamelle pendant la période sèche ou pendant la lactation (lots 3 et 4 ), le rapport a une valeur comprise entre I et 2, jusqu'au moment de l'injection de rappel par voie générale. Le rapport suit alors une élévation nette sur les brebis du lot 3, vaccinées pendant la lactation, faible sur les brebis du lot 4 , vaccinées pendant la période sèche, mais temporaire dans les 2 cas. Cette élévation résulte d'une montée importante des titres sériques sans répercussion notable sur les titres du lactosérum, comme dans le cas des antitoxines staphylococciques. Les titres sériques moyens passent en effet, dans les lots 
3 et 4 , respectivement, de 4,5 à 7,3 , et de 7,0 à 8,5 alors que les titres du lactosérum vont de 3,0 à 3,8 et de 6,0 à 6,6 .

Ces résultats montrent que la vaccination intramammaire avec l'antigène brucellique provoque l'apparition d'agglutinines dans le lait à un titre voisin de celui du sérum, sans modifier le rapport des titres des anticorps témoins marqués, et que ce titre des agglutinines dans le lait se maintient de façon durable.

Il faut ajouter que, comme dans le cas précédent, les titres sériques sont plus élevés après vaccination dans la mamelle - pendant la période sèche - -, avec une même dose d'antigène, que par voie sous-cutanée, mais que la vaccination pendant la lactation donne au contraire des titres inférieurs. Par exemple, au prélèvement $\mathrm{n}^{0} 4$, les titres étaient, dans le lot 3 (intramammaire, pendant lactation) de 4,83 ; dans le lot 4 (intramammaire, période sèche) de 7,50; et le lot 5 (voie générale) 6,2. La comparaison 4 versus 5 n'est toutefois pas significative $(F=4,06$, avec $F \quad 0,05$ $=4.67)$.

\section{DISCUSSION}

Des résultats précédents, un certain nombre de conclusions peuvent être tirées :

I. sur brebis exemptes d'inflammation de la mamelle, vaccinées par voie générale, le rapport, entre les titres dans le sérum et le lactosérum d'un anticorps donné, varie dans des limites étroites. En dehors de la période colostrale, non étudiée, ce rapport est, pendant les I2 premières semaines de la lactation, voisin de 25 . Ce fait a été établi pour les anticorps suivants : agglutinines brucelliques, agglutinines salmonelliques, $\mathrm{O}$ et $\mathrm{H}$, antitoxines staphylococciques $\alpha$ et $\beta$. Nous ne pouvons pas assurer qu'il soit généralisable à tous les anticorps et à toutes les espèces bien que ce soit assez vraisemblable. LASCELLES, OUTTERIDGE et MACKENZIE (I966) en utilisant des $\gamma-7$ S. globulines marquées, ont obtenu, sur 3 brebis, un rapport de 12,5 à 20 .

2. Après injection d'un antigène dans la mamelle, le rapport des titres sérum sur lactosérum de l'anticorps correspondant, peut:

a) n'être pas sensiblement modifié; c'est ce que nous avons obtenu avec les antigènes staphylococciques, solubles ou particulaires, anatoxines et corps microbiens ;

b) tendre vers une valeur voisine de $I$, par une élévation remarquable du titre dans le lactosérum. Dans ce travail, c'est ce que nous avons obtenu avec l'antigène cellulaire de Brucella. Dans ce cas, le rapport des titres des autres anticorps n'est pas modifié.

Ce fait peut être interprété soit comme résultant de la formation de l'anticorps brucellique par le système lymphatique de la mamelle avec évacuation par le lait, soit comme résultant d'une modification spécifique du passage de 1'anticorps existant au préalable dans le sérum sanguin ou produit à la suite de l'injection d'antigène. Le fait que sur certains des animaux le titre du lactosérum soit plus élevé que celui du sérum exclut cette hypothèse, à moins d'imaginer un processus de concentration spécifique, comme il $\mathrm{y}$ a une concentration non spécifique des globulines pendant la phase colostrale. Cette hypothèse paraît bien peu vraisemblable en raison de l'importance et de la durée du phénomène. OUTTERIDGE, ROck et LASCELLES (I965), LASCELIES, OuTteRIDGe et MacKenzie (I966) ont en effet obtenu, sut des 
cas individuels, des rapports de $0, \mathrm{I} 7$ et 0,25 , et ces auteurs ont signalé, ce que nous avons aussi observé, la persistance d'un rapport égal à I au cours de la lactation suivante.

Ces auteurs (OUTTERIDGE, Rock et LAScELIES, I965; LASCELILES, OUTTERIDGE et MACKENZIE, I966 ; MACKENZIE, OUTTERIDGE et LASCELIES, I966 ; OUTTERIDGE et LASCELIES, I967) utilisent des antigènes comparables aux nôtres, mais un dispositif expérimental différent. Ils n'ont pas pris un témoin anticorps spécifique marqué pour mesurer le taux de passage normal, mais seulement, dans quelques cas, des $\gamma-7 \mathrm{~S}$ globulines marquées à 1'iode radioactif. Ils ont comparé les rapports sérumlactosérum dans le lait des deux glandes mammaires stimulées par deux antigènes différents, et montré que chaque glande répond spécifiquement à 1'antigène qu'elle a reçu. Il y a toutefois des discordances entre nos résultats et les leurs sur plusieurs points : ils n'observent pas de réponse de la mamelle à l'injection d'antigène brucellique pendant la lactation, mais seulement quand celle-ci a lieu pendant la période sèche ; encore observent-ils des différences inexplicables d'une année à l'autre. Ils interprètent la réponse à l'injection intramammaire d'anatoxine staphylococcique en se basant sur des comparaisons de titre entre quartiers, ce qui ne constitue pas à notre avis, la preuve d'une synthèse locale d'anticorps antitoxiques (Prommet et LE GALL I963 b).

Depuis les revues de LAscelles (I963) et de CAmpbeil, et Petersein (I963), d'autres auteurs ont étudié la production d'anticorps spécifiques par la mamelle, en utilisant comme antigène des virus (THOMAS et LECLERC, I96I ; MITCHELL, I965; MiTcheis, Guérin et PASIEKA, I967), de 1'anatoxine staphylococcique (RIchou et Quinchon, I96I) des antigènes bactériens divers (SARwAR, Campbei, et PétersenN, I964). Ces auteurs constatent la présence d'anticorps dans le lait après injection d'antigène dans la mamelle, sans toutefois pouvoir assurer, pour n'avoir pas tenu compte du passage dû à l'inflammation, que ces anticorps n'ont pas une origine extramammaire.

L'ensemble des faits observés peut se résumer à ceci : les anticorps du lait ont deux sources. Les uns viennent du système sanguin par passage à travers le tissu mammaire : ce passage est approximativement à taux constant, sauf en cas d'inflammation, où il est augmenté. Les autres, après stimulation antigénique locale, sont formés dans le système lymphatique de la mamelle avec "excrétion " des anticorps dans le lait et dans le sang. Tous les antigènes ne sont pas susceptibles d'induire cette synthèse locale; nous ne savons pas actuellement les raisons de cette différence de comportement.

Il reste, en dehors de ce dernier point, beaucoup d'inconnues au problème que certaines observations faites dans ce travail mettent en évidence. Nous en retiendrons deux : l'injection d'un antigène dans la mamelle peut donner des titres anticorps sanguin plus élevés que l'injection d'une même dose d'antigène sous la peau. C'est, dans ce travail, ce que nous avons obtenu avec l'antigène anatoxines staphylococciques, que l'injection ait eu lieu pendant la période sèche ou pendant la lactation, et avec l'antigène brucellique injecté pendant la période sèche. La différence entre ces deux types d'antigène selon le stade de lactation peut être due à leur nature soluble ou particulaire: pendant la lactation, l'antigène injecté dans la mamelle est éliminé par la traite après Iz heures de contact, s'il n'est pas résorbé à ce stade.

Le passage des anticorps du sérum dans le lactosérum n'est pas un phénomène 
rapide, comme le taux constant pourrait le faire croire. Nous avons vu, en effet, que les injections de rappel par voie générale, qui font monter les titres sériques, font également monter le rapport sérum-lactosérum pour une durée approximative de I 2 jours, avant que 1'équilibre normal résultant du passage soit rétabli. Ce délai serait le délai normal de passage, ce qui laisse à penser qu'il y a un remaniement de la molécule d'anticorps au moment du passage à travers la mamelle.

Reçu pour publication en arril $\mathrm{r} 968$.

\section{REMERCIEMENTS}

Nous remercions M. G. MocQuoT, directeur de la Station centrale de Technologie des Produits animaux, où ce travail a été fait pour les discussions fructueuses sur l'organisation de l'expérience et révision du manuscrit.

\section{SUMMARY}

\section{THE ORIGIN OF MILK ANTIBODIES}

Ewes were vaccinated either by infusion of antigens in the mammary gland (local vaccination) or by systemic (subcutaneous) injection, and corresponding antibodies were titrated in serum and whey.

After systemic vaccination of 27 ewes, with Salmonella and Brucella cellular antigens, a constant relationship was found between titers of agglutinins in serum and whey (expressed as $\log _{2}$ of dilution, Salmonella $\mathrm{O}$ and $\mathrm{H}$, and Brucella, fig. I) on the 58 th day of lactation. Titers in whey were about twenty-five times smaller than in serum. This relationship was not affected by injection in the udder of a non related (staphylococcal) antigen.

After local or systemic (table I) infusion, with a mixed vaccin, (Brucella plus staphylococcal toxoids alpha and beta antigens) and after systemic vaccination with Salmonella, antigen titers of Brucella, Salmonella $\mathrm{O}$ and $\mathrm{H}$ agglutinins and staphylococcal antitoxins alpha and beta were recorded in serum and whey of $2 \mathrm{I}$ ewes during the first $\mathrm{I} 2$ weeks of lactation. Ratios between serum and whey titers are expressed as difference between $\log _{2}$ values. Brucella agglutinins in whey increased to a level about half that of the serum, without any noticeable change in ratios of others non related antibodies (fig. $2,3,4,5,6$ ), whether the infusions were done systemically or in the udder. These results are discussed from the point of view of local synthesis of antibodies to some kind of antigens.

\section{RÉFÉRENCES BIBLIOGRAPHIQUES}

Asofsky R., SMaLL P. A., I 967. Colostral Immunoglobulin A : synthesis in vitro of T. chain by rabbit mammary gland. Science, 158, 932-933.

CAmpbell B., Petersen W. E., 1963. Immune milk. A historical survey. Dairy Sci. Abstr., 25, $345 * 358$.

Dixon F.S., WEIGLE W: O., VASQUEZ J. J., I $96 \mathrm{I}$. Metabolism and mammary secretion of serum proteins in the cow. Lab. Inves., 10, $216-237$.

LASCELlES A. K., 1963. A review of the literature on some aspects of immune milk. Dairy Sci. Abstr., 25, 359-364.

Lascelles A. K., OutTeridge P. M., Mackenzie D. D. S., 1966 . Local production of antibody by the lactating mammary gland following antigenic stimulation. Aust. J. exp. Biol. med. Sci., 44, 169-180. 
Mackenzie D. D. S., OutTeridge P. M., Lascelles A. K., 1966. Transfer of circulating $\gamma$-globulin into milk and efferent mammary lymph during experimental mastitis. Aust. exp. Biol. med. Sci., 44, r81-196.

Mrichell C. A., 1965. Production of antibodies in the mammary gland with especial reference to virus neutralizing antibody. Can. J. Comp. Med., 29, 262-265.

Mitchell C. A., Gutrin L. F., Pasieka A. E., ig67. Antibody production in milk serum after virus instillation of goat mammary gland $I$. Responses to influenza virus, mumps virus, and adenovirus 3. Can. J. Microbiol., 18, 1069-1078.

Outteridge P. M., Rock J. D., LAscelles A. K., I965. The immune response of the mammary gland and regional lymph node following antigenic stimulation. Aust. J. exp. Biol. med. Sci., 48, 265-274.

OutTeridge P. M., LAscelles A.K., 1966. The cellular and immune response in milk and regional lymph during experimental mastitıs. Res. Vet. Sci., 7, 360-367.

OUtTERIdGe P. M., LAscel.Les A. K., 1967. Local immunity in the lactating mammary gland following the infusion of staphylococcal toxoids. Res. Vet. Sci., 8, 313-320.

Pierce A F., Feinstein A., I 965. Biophysical and Immunological studies on bovine immune globulins with evidence for selective transport within the mammary gland from maternal plasma to colostrum. Immunology, 8, 106-г 23.

Pillet J., ORTa B., Foucaud M., ig60. Recherches sur l'individualisation sérologique des staphylocoques. Étude de la spécificité des types ro, I 1, 12, 13. Annls. Inst. Pasteur, 98, 701-708.

Plommet M., Le Gall A., 1963. a. Mammite staphylococcique de la brebis III. Recherches sur l'immunité antibactérienne et antitoxique. Annls. Inst. Pasteur, 104, 780-796.

Plommet M., Le Gall A., I963. b. Mammite staphylococcique de la brebis IV. Vaccination locale. Annls Inst. Pasteur, 105, 535-543.

Richou R., QuinchoN C., 196r. Contribution à l'étude de l'immunité antistaphylococcique développée, chez la Vache, à la suite d'injections intramammaires d'antigènes spécifiques. Revue Immunologie, 25, 209-222.

Sarwar M., Campbell B., Petersen W. E., 1964. Production of antibody in mammary gland of pregnant, non lactating and lactating cows, evoked by polyvalent antigen with reference to dosage and frequency of immunization. Can. J. comp. Med., 28, $183^{-192 .}$

Thomas A., Leclerc J., 196r. Recherches préliminaires sur l'obtention d'anticorps du virus de la fièvre aphteuse dans le lait de vache, après injection du virus dans le canal du trayon. $C$. $R$. Acad. Sci., 258 , I690-I692. 